\title{
KREATIVITAS BARNAWI DALAM MUSIK BUNDENGAN DI MASYARAKAT KABUPATEN WONOSOBO PROVINSI JAWA TENGAH
}

\author{
Ester Risnauly Berutu \\ TVRI Kalimantan Timur \\ esther17risnauly@gmail.com
}

\begin{abstract}
Abstrak
Bundengan adalah sebuah alat musik dari Kabupaten Wonosobo berbahan dasar dari bambu. Alat musik bundengan lahir dari kreatifitas seniman karawitan saat sedang beristirahat menggembalakan bebek yang memodifikasi kowangan atau tudung miliknya menjadi sebuah alat musik, dia adalah Barnawi. Bagian dalam Bundengan terdapat 4 buah senar, jika dibunyikan akan menghasilkan suara seperti instrumen kethuk, kenong, kempul dan gong dalam gamelan Jawa.Alat musik ini dimainkan oleh satu orang. Jika dimainkan oleh dua orang, maka satu orang yang lain sebagai wiraswara. Memiliki banyak peminat dari berbagai kalangan bundengan pun mengalami perkembangan yang pesat, meskipun sempat mati suri karena meninggalnya Barnawi, alat musik bundengan bangkit kembali bersama Munir yaitu adik dari Barnawi yang berkerjasama dengan Dinas Pariwisata dan Kebudayaan, Budayawan, maupun orang-orang yang menginginkan bundengan tetap lestari. Fungsi musiknya adalah sebagai pengungkapan emosional, hiburan, pengiring tarian dan kesinambungan budaya.
\end{abstract}

Kata kunci : Bundengan, Kreativitas

\begin{abstract}
Bundengan is a musical instrument from the Wonosobo Regency which is made of bamboo. Bundengan musical instrument was born from the creativity of musical artists while resting herding ducks which modified their kowangan or hood into a musical instrument, he was Barnawi. Inside the Bundengan there are 4 strings, if it is sounded it will produce sounds such as instruments of kethuk, kenong, kempul and gong in Javanese gamelan. This musical instrument is played by one person. If it is played by two people, then one person is a singer. Having a lot of enthusiasts from various bundengan also experienced rapid development, although it was near death due to the death of Barnawi but the bundengan revived with Munir, the younger brother of Barnawi who collaborated with the Department of Tourism and Culture, Culture, and people who wanted a permanent bundengan sustainable. The function of the music is an as emotional expression, entertainment, accompaniment of dance and cultural continuity.
\end{abstract}

Keywords : Bundengan, Creativity 


\section{A. Pendahuluan}

Setiap wilayah dan suku bangsa Indonesia, pasti memiliki kesenian tradisional yang berkembang di daerah itu. Salah satunya ada di Desa Maduretno, Kecamatan Kalikajar, Kabupaten Wonosobo, Provinsi Jawa Tengah, Kesenian tersebut adalah bundengan. Bundengan adalah alat musik petik yang terbuat dari bambu. Bundengan diketahui sudah ada sejak abad ke-12 yaitu jaman pertengahan masa kerajaan Majapahit masih berjaya. Pendapat ini didasari dari isi kitab Wretta Sancaya karya Empu Tanakung yang didalamnya menyebut masyarakat pada waktu itu telah mengenal bentuk kesenian yang bernama “Tudung”. Bahkan juga disebut dengan istilah lain yaitu "Pether".

Alat musik ini awalnya merupakan tudung atau topi yang disebut Kowangan, biasanya digunakan oleh penggembala bebek saat berteduh dari terik matahari dan hujan. Berbentuk segitiga memanjang, terbuat dari kerangka bambu tebal yang dianyam, dan pada bagian luarnya dilapisi dengan slumpring (pelepah batang bambu) yang kemudian diikat dengan tali ijuk. Penyebutan bundengan untuk instrumen ini, diambil dari hasil bunyi insrumen tersebut yang menghasilkan bunyi dengung, sengau atau bindeng. Sifat bunyi dengung ini ditafsirkan dengan istilah bundheng. Secara 30 sederhana hal tersebut merupakan bagian dari etimologi yang berakar dari kata "bindeng" dan imbuhan "an" yang menegaskan makna benda atau alat, sehingga lazim dijumpai dengan istilah bundengan.

Alat musik bundengan lahir dan tumbuh dari upaya memodifikasi fungsi Kowangan. Kowangan tersebut kemudian dimodifikasi dengan kreativitas dalam mengeksplorasi musik. Kreativitas adalah menemukan sesuatu yang "baru" atau hubungan-hubungan baru dari sesuatu yang telah ada. Salah satu contoh seniman yang menciptakan alat musik baru adalah Barnawi, seorang seniman dengan latar belakang Karawitan Jawa. Barnawi biasanya bekerja sebagai petani dan menggembala bebek untuk memenuhi kebutuhan rumah tangganya. Sambil mengembala bebek, Barnawi mulai merakit kowangan dengan menambah 4 ijuk yang jika dipetik akan mengeluarkan suara yang menyerupai seperangkat gamelan dan menambah 3 bilah bambu yang akan mengeluarkan suara seperti kendang, maka terbentuklah sebuah alat musik yang sekarang dinamakan bundengan.

Awalnya Barnawi memainkan alat musik tersebut hanya untuk menghibur diri sendiri. Setelah itu Barnawi memperkenalkan alat musik tersebut kepada keluarganya dan masyarakat 
sekitar. Bundengan semakin dikenal oleh masyarakat sekitar dan mendapat respon yang baik. Berjalannya waktu, kesenian bundengan mengalami "mati suri" karena meninggalnya Barnawi sang seniman bundengan pada tahun 2012. Tahun 2015 kesenian bundengan muncul kembali, tetapi meskipun sempat "mati suri" bundengan tetap mendapat respon yang baik dari masyarakat Wonosobo. Terbukti dengan maraknya masyarakat menyajikan bundengan dalam acara mereka. Pelestarian alat musik tersebut dilanjutkan kembali oleh Munir, Buchori, Budayawan, Dinas Kebudayaan dan Pariwisata, serta semua yang menyukai bundengan agar kesenian ini kembali dikenal lagi.

\section{B. Metode Penelitian}

Metode penelitian yang digunakan adalah metode penelitian deskriptif analisis dan melakukan pendekatan secara etnomusikologis. Penelitian kualitatif adalah penelitian yang bermaksud untuk memahami tentang apa yang dialami oleh subyek penelitian, seperti perilaku, persepsi, motivasi, tindakan, dan lain-lain secara holistik dan dengan cara deskripsi dalam bentuk kata-kata dan bahasa dalam suatu konteks yang alamiah.

Penggunaan Metode kualitatif ini diharapkan dapat membantu agar pertanyaan-pertanyaan pada rumusan masalah dapat terjawab, yaitu mencari fakta dibalik suatu fenomena kemunculan musik bundengan ini. Metode ini dipilih untuk membantu dalam hal mendeskripsikan serta menganalisa suatu fenomena yang terjadi melalui pengamatan langsung ke lapangan.

Pendekatan secara etnomusikologis dilakukan dalam rangka analisa teks dan konteks yang akan dilakukan oleh peneliti. Analisis teks berkaitan dengan analisa kejadian-kejadian musikal sedangkan analisa konteks untuk menganalisa kejadian-kejadian yang terjadi pada masyarakat yang berkaitan erat dengan kejadian musikal.

\section{Hasil dan Pembahasan}

\section{Eksistensi Bundengan di Masyarakat} Wonosobo

Keberadaan bundengan secara historis tidak lepas dari keberadaan kowangan, karena seni pertunjukan ini berawal dari upaya memodifikasi fungsi kowangan menjadi alat musik. Keberadaan bundengan memang tercipta dari penggunaan kowangan dalam kehidupan masyarakatnya sehari-hari. Keberadaan bundengan tetap eksis dalam masyarakat Kabupaten Wonosobo dipengaruhi oleh faktor internal dan faktor eksternal. Faktor internal meliputi faktor keturunan yaitu alat musik ini tetap ada karena diajarkan secara turun-temurun kepada saudara dan anak-anaknya yang bahkan sekarang 
diajarkan kepada generasi muda seperti diajarkan di SMPN 2 Selomerto dan ada faktor lingkungan yaitu mendapat dukungan dari tetangga sampai kepada seniman, budayawan dan dari pihak pemerintah seperti Dinas Kebudayaan dan Pariwisata, juga Dinas Informasi dan Komunikasi. Sehingga alat musik tersebut berkembang dengan pesat. Sedangkan faktor eksternal meliputi faktor teknologi informasi yaitu memanfaatkan media informasi online untuk mengenalkan dan mempromosikan bundengan. Hal ini dapat membuat bundengan dikenal bukan hanya di dalam tapi diluar Wonosobo.

\section{Proses Terciptanya Kreativitas Bundengan}

Persoalan ini mengacu pada bentuk kreativitas penciptanya. Utami Mundandar dalam bukunya Kreativitas dan Keberbakatan memaparkan tentang kreativitas dengan pendekatan konsep 4P. Utami Munandar menyebut keempat jenis definisi tentang kreativitas ini sebagai “Four P's of Creativity: Person (pribadi), Procces (proses), Press (dorongan), dan Product (produk)". Unsur pertama pada fase ini adalah Pribadi (person). Hal ini adalah penciptanya berinteraksi dengan lingkungannya. Ungkapan seperti inilah yang memicu menimbulkan ide-ide baru dan produk-produk yang inovatif. Unsur kedua pada fase ini adalah proses (process).
Definisi tentang proses kreatif pada dasarnya adalah berawal dari menemukan suatu masalah, penyelesaian, hingga hasil akhir.

Unsur ketiga adalah pendorong (press) atau dorongan dalam berproses kreatif. Dorongan dibagi menjadi dua yaitu dorongan dari dalam (internal) dan dorongan dari luar (eksternal). Indikasi dari dorongan internal nampak pada motivasi pelakunya dalam menciptakan bundengan atas dasar kemungkinan menemukan bunyi-bunyian yang dapat dihasilkan di dalam kowangan yang akhirnya menjadi suntikan untuk menghasilkan bundengan yang sempurna atau lebih terkonsep. Kemudian pendorong eksternal terletak pada lingkungan kondisif yang tersalurkan pada keadaan santai dalam waktu luang di sawah atau ladang sehingga lingkungan itu lebih kondusif lagi untuk menghibur diri melalui musik. Kemudian unsur keempat dan yang terakhir adalah produk (product). Hasilnya sangat nyata hingga lahir bermacam musik yang berembrio dari kowangan itu. Proses kreatif itulah muncul alat musik dan sajian komposisi musik. Maka peran kreativitaslah yang memberi andil hingga manfaatnya masih terasa sampai sekarang.

\section{Bentuk Penyajian Bundengan}


Salah satu pertunjukan musik bundengan yaitu yang mana musik bundengan merupakan bagian dari Solidarity Tour yang dilaksanakan oleh PSI (Partai Solidaritas Indonesia) dalam acara puncaknya yaitu Solidarity Night. Tempat acaranya diadakan di Hotel Surya Asia yang beralamat di Jl. Jenderal Ahmad Yani No.137, Wonosobo Timur, Kabupaten Wonosobo. Acara Solidarity Night diselenggarakan pada tanggal 22 februari 2019 hari jumat di malam hari sekitar pukul 19.30 WIB. Keseluruhan pemain dalam pertunjukan musik bundengan berjumlah empat orang pemain. Pelaku yang memainkan bundengan berjumlah satu orang pria yaitu Munir. Terdapat vokal yang dibawakan oleh satu orang pria yaitu Buchori. Vokal tersebut dinyanyikan dengan menggunakan bahasa jawa. Terakhir adalah penari tari lengger yang berjumlah satu orang wanita dan satu orang pria. Prosesi sebelum mulai memainkan musik bundengan Buchori sebagai wiraswara mengawali acara tersebut dengan memberi salam kepada para hadirin. Pemusik bundengan memakai Blangkon, kemeja batik dan celana kain hitam. Sedangkan para penari menggunakan kemben, kain jarit, ubetan selendang, dan mahkota dengan bulu khas yang panjang.
Musik bundengan pun dibuka dengan lagu Wonosobo Asri yang bercerita sedikit tentang macam-macam wisata alam, makanan yang khas dan oleh- oleh dari Wonosobo. Selesai lagu Wonosobo Asri dilanjutkan dengan lagu Sulasib Sulandana yang menjadi lagu andalan atau lagu yang selalu dibawakan setiap pementasan musik bundengan. Setelah lagu Sulasib sulandana maka dilanjut dengan lagu Rangu-Rangu. Lagu rangu-rangu menjadi lagu yang dimainkan untuk mengiringi tarian topeng lengger. Tari Lengger adalah salah satu tarian tradisional dari Jawa Tengah yang dimainkan oleh seorang laki-laki dan seorang perempuan dengan tema kesenian rakyat yang menggunakan topeng. Lagu pun berakhir dan berlanjut ke lagu yang berjudul Gondong Keli. Lagu gondong keli ini juga menjadi lagu penutup untuk pertunjukan pada acara itu. Sebelum turun dari panggung Buchori pun mengucapkan terima kasih untuk kesempatan yang diberikan untuk pertunjukan musik bundengan dan mengajak para generasi muda untuk melestarikan kesenian tradisional khas daerah Wonosobo.

Berikut ini adalah transkripsi salah satu lagu yang sering dimainkan dalam musik bundengan dengan bentuk notasi kepatihan. 
Ester Risnauly Berutu (Kreatifitas Barnawi...) pp. 29-40

\section{"Sulasih Sulandana"}

Transkriptor : Willy day onamlai

Buko

$$
\begin{aligned}
& -\quad-23-1 \quad-332 \\
& \text { - } \quad 5 \quad \text { - } 53 \\
& \text { Tau-ne pa-pat li-mo } \\
& -\quad-\quad- \\
& \begin{array}{llll}
6 & 5 & 3 & 2
\end{array} \\
& \mathrm{Ne}-\mathrm{ga}-\mathrm{ra}-\mathrm{ne} \quad \text { wis mer de ka } \\
& 356 \text { i }-\ldots+\div 6 \\
& 5 \\
& 2 \quad 2 \quad 2 \quad 2 \quad-\ldots+\overline{. \overline{32}} 1 \\
& \begin{array}{llll}
1 & 1 & 2 & 3
\end{array} \\
& \text { Pra lam bang - e gam bar ga ru } \\
& . . \overline{2} 3 \quad \bar{i} \quad \mathrm{i} \quad \mathrm{i} \quad \mathrm{i} \quad-56 \quad \mathrm{i} \cdot \overline{\overline{i 6 \overline{1}}} \\
& \overline{65} 5 \\
& \text { da ade da sar pan }-\mathrm{ca}-\mathrm{si}-\mathrm{la}
\end{aligned}
$$




\section{Bait Pokok}

$$
\begin{aligned}
& \begin{array}{llllllllll}
\ldots & . & 2 & 3 & 5 & \ldots & 3 & 3 & 2 & 3
\end{array} \\
& \text { Su la sih su lan do no }
\end{aligned}
$$

$$
\begin{aligned}
& 356 \text { i }-----1 \\
& \therefore 65532 \\
& \text { menyan putih pan gun - dang de - wo }
\end{aligned}
$$

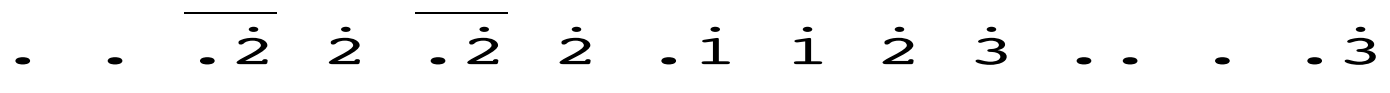

$$
\begin{aligned}
& \dot{2} i \\
& \text { Ana de - wa de }
\end{aligned}
$$

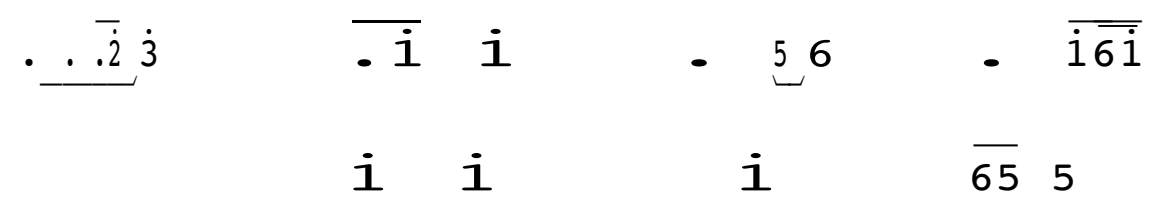


Lagu ini nantinya dimainkan dengan iringan dari bundengan yangmempunyai pola melodi pada Senar dan ritmis pada kendang. Pola permainan yang terdapat pada senar dengan fungsi mengimitasi gamelan sebagai berikut :

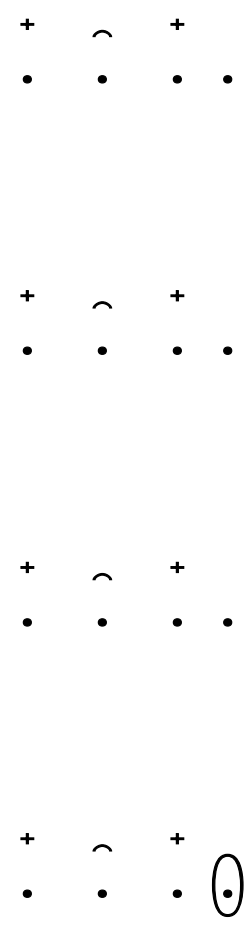

Keterangan :

$+\quad$ : Kethuk

- Kenong

: Kempul

Bundengan biasa dimainkan oleh satu orang menggunakan kedua tangannya. Adapun teknik dasarnya adalah memetik sumber bunyi menggunakan jari tangan. Terdapat dua bentuk pola permainan pada musik Bundengan yaitu pola ajeg dan kondisional. Ajeg mempunyai arti tetap dan tidak berubah-ubah. Pola permainan ini yang dimainkan dengan tangan kanan yang berfungsi sebagai seperangkat alat gamelan. Hal tersebut disebabkan imitasi bunyi yang diciptakan pada senar. Bunyi yang dihasilkan adalah kethuk, kenong, kempul dan gong. Pola kondisional dimainkan pada tangan kiri yang berfungsi sebagai bunyi kendang. Pola permainan yang terdapat pada bilah bambu dengan fungsi mengimitasi kendang sebagai berikut 
Selonding

Vol.17, No. 2: September 2021

Jurnal Etnomusikologi

$$
\begin{aligned}
& . P-p \text { t } p \quad-\overline{p p} \overline{. P} \overline{t P} \overline{. P} d \overline{. P} d \\
& \overline{. p} \quad \overline{d d} \quad \overline{. d} \quad b \\
& \overline{. p} \cdot p \overline{t p} \cdot \overline{p p} \overline{. p} \overline{. t} \overline{p b} \overline{\cdot t} \overline{p b} \overline{. p} \overline{. p} \overline{d d} \overline{. d} b
\end{aligned}
$$

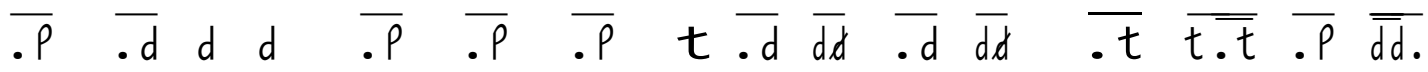

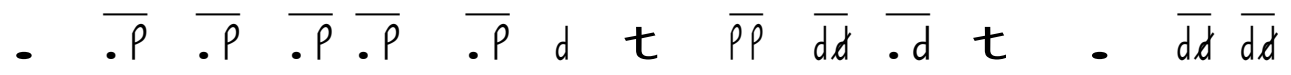

Keterangan :

P : tung

d : dheng

d : dhet

t : tak

b: : bem

37 
Selama permainan bundengan pola kendangan tersebut akan diulangi terusmenerus, tetapi tidak sepenuhnya sama karena secara garis besar berupa improvisasi. Pola tersebut tidak seutuhnya sama apabila disajikan dengan lagu lain seperti Sarindoro, Kinayakan, Mandung-mandung, dan lain sebagainya. Permainan instrumen kendang sangat kondisional agar dapat menyesuaikan dengan lagu yang disajikan.

\section{Simpulan}

Keberadaan musik bundengan yang berawal dari kreatifitas seorang penggembala bebek yang juga berlatar belakang seniman karawitan Jawa yaitu Barnawi yang mengubah sebuah tudung berbentuk segitiga memanjang ke bawah itu menjadi alat musik. Terdapat 4 unsur terwujudnya kreativitas tersebut, yaitu Unsur pertama adalah pribadi (person). Dalam hal ini adalah penciptanya berinteraksi dengan lingkungannya. Unsur kedua adalah proses (process). Definisi tentang proses kreatif pada dasarnya adalah berawal dari menemukan suatu masalah, penyelesaian, hingga hasil akhir. Unsur ketiga adalah pendorong (press) atau dorongan dalam berproses kreatif. Dorongan dibagi menjadi dua yaitu dorongan dari dalam (internal) yaitu motivasi dan dorongan dari luar (eksternal) yaitu lingkungan. Unsur keempat dan yang terakhir adalah produk (product). Hasilnya sangat nyata hingga lahir bermacam musik yang berembrio dari kowangan itu dan sebuah alat musik yaitu bundengan.
Alat musik yang berbahan dari bambu tersebut hingga sekarang masih dilestarikan bahkan sedang diupayakan menjadi kesenian khas sekaligus identitas dari masyarakat Wonosobo. bundengan yang memiliki bentuk berbeda atau unik dari yang lain dan memiliki suara yang menyerupai gamelan Jawa ini sangat familiar di telinga masyarakat di provinsi Jawa Tengah sehingga mendapat apresiasi yang begitu besar dari masyarakat setempat. Dukungan dari masyarakat bahkan sampai kepada pihak pemerintah dan tokoh-tokoh seniman Wonosobo menjadi faktor pendukung keberadaan bundengan yang masih tetap eksis sampai sekarang. Tidak hanya re- generasi yang diturunkan di keluarga dari Barnawi ke anak dan saudaranya Munir, sekarang Munir pun memberi kesempatan untuk siapapun yang ingin belajar bundengan untuk berlatih kepadanya, bahkan sudah ada sekolah menegah pertama yang menjadi pelopor pembelajaran bundengan yaitu: SMPN 2 Selomerto.

Kecanggihan teknologi juga membantu pesatnya perkembangan 
bundengan dengan menjadi pusat informasi digital sehingga semua orang dapat mengetahui apa itu bundengan dan tidak sedikit dari mereka ikut membantu melestarikan musik bundengan seperti membagikan informasi dengan social media yang dipunya. Musik bundengan di mainkan pada acara Solidarity Tour di puncak acaranya Solidarity Night yang di adakan oleh PSI (Partai Solidaritas Indonesia). Acara tersebut dilaksanakan pada tanggal 22 februari 2019 hari jumat di malam hari sekitar pukul 19.30 WIB yang di pentaskan di Hotel Surya Asia yang beralamat di Jl. Jenderal Ahmad Yani No.137, Wonosobo Timur, Kabupaten Wonosobo. Keseluruhan pemain dalam pertunjukan musik bundengan berjumlah empat orang pemain. Pelaku yang memainkan bundengan berjumlah satu orang pria yaitu Munir. Terdapat vokal yang dibawakan oleh satu orang pria yaitu Buchori dan dua orang penari lengger. Musik bundengan memainkan empat lagu yaitu wonosobo asri, sulasih sulandana, rangurangu dan yang terakhir gondong keli. Munir dan Buchori sebagai pemain bundengan memakai Blangkon, kemeja batik dan celana kain hitam. Sedangkan para penari menggunakan kemben, kain jarit, ubetan selendang, dan mahkota dengan bulu khas yang panjang.

\section{E. Daftar Pustaka}

Abdulloh, Muhammad Sa'id. 2017. "Kajian Organologi Musik Bundengan Wonosobo". Skripsi untuk mencapai derajat sarjana S-1 pada program studi etnomusikologi, fakultas seni pertunjukan, Institut Seni Indonesia Surakarta.

\section{Bakker SJ, J.W.M. 1984. Filsafat Kebudayaan Sebuah Pengantar. Yogyakarta: Kanisius.}

Boskoff, Alvin. 1964. "Recent Theories of Social Change" dalam Sociology and History Werner J. Cahnman dan Alvin Boskoff (eds). London: The Free Press of Glencoe.

Berutu, Ester Risnauly. Kreatifitas Barnawi dalam Musik Bundengan di Masyarakat Kabupaten Wonosobo Provinsi Jawa Tengah. Skripsi S-1 Program Studi Etnomusikologi FSP Institut Seni Indonesia Yogyakarta, 2019

Haviland, William A. 1988. Antropologi Jilid 2 Terj R.G Soekadijo. Jakarta: Erlangga. Kayam, Umar. 1981. Seni, Tradisi dan Masyarakat. Jakarta : Sinar harapan.

Kistanto, Nurdien. 2008. Sejarah Wonosobo. Wonosobo:PT.Bhakti Tunas Perkasa.

Koentjaraningrat. 2009. Pengantar Ilmu Antropologi. Jakarta: PT Rineka Cipta

Koentjaraningrat. 1984. Kebudayaan Jawa. Jakarta: Balai Pustaka.

Kunst, Jaap. Music In Java: Volume 2. Hague : Martinus Nijhoff.

Moleong, Lexy J. 2005. MetodePenelitian 
Kualitatif Bandung: PT. Remaja Rosdakarya.

Munandar, Utami. 2002. Kreativitas dan Keberbakatan Strategi Mewnjudkan Potensi Kreatif dan bakat. Jakarta: PT.Gramedia Pustaka Utama

Nakagawa, Shin. 2000. Musik dan Kosmos : Sebuah Pengantar Etnomusikologi Yogyakarta : Yayasan Obor Indonesia.

Nettl, Bruno. 2005. The Study of Ethnomusicology: Thirty-one Issues and Concepts.USA: University of Illinois Press.

Salamun, dkk. 2002. Budaya Masyarakat Suku Bangsa Jawa di Kabupaten Wonosobo Jawa Tengah. Yogyakarta : UPT Perpustakaan ISI.

Soedarsono, R.M. 2001 Metode Seni Pertunjukkan dan Seni Rupa. Bandung: Masyarakat Seni Pertunjukan Indonesia.

Santoso, Rinto Budi. 2016. "Rekonstruksi Sejarah dan Perkembangan Kesenian Bundengan di Desa Madu Retno, Kecamatan Kalikajar, Kabupaten Wonosobo". Tesis untuk mencapai derajat sarjana S-2 program studi Pendidikan lmu Pengetahuan Sosial, Universitas PGRI Yogyakarta.

Sunaryadi. 2000. Lengger : Tradisi dan Transformasi. Yogyakarta: Lembaga Penelitian Institut Seni Indonesia Yogyakarta.

Supanggah, Rahayu. 2007. Bothekan Karawitan II: Garap. Surakarta: ISI Press Surakarta

Surendra, Wilia Beny. 2009. "Bentuk
Penyajian dan Komposisi Lagu dalam Kesenian Bundengan di Desa Maduretno Kecamatan KajiKajar Kabupaten Wonosobo" Skripsi untuk mencapai derajat sarjana S-1 pada program studi Pendidikan Seni Musik, Fakultas Bahasa dan Seni, Universitas Negeri Yogyakarta, Yogyakarta.

Spradley, James P. 2006. Metode Etnografi: Edisi Kedua Yogyakarta: Tiara Wacana.

Wahyudi, Ahid. 2006. "Bentuk dan Fungsi Seni Koangan Desa Bumitirta, Kecamatan Selomerto, Kabupaten Wonosobo, Provinsi Jawa Tengah". Skripsi untuk mencapai derajat sarjana S-1 pada program studi Karawitan, Fakultas Seni Pertunjukan, Institut Seni Indonesia Yogyakarta.

https://wonosobokab.go.id/website/index. php/2014-02-01-04-40-52/selayangpandang/geografis-kabupatenwonosobo/itemlist/category/9-selayangpandang? start $=5$, Diakses pada tanggal 05 Juli 2019.

https://wonosobokab.go.id/website/index .php/rpjmd/itemlist/category/10-potensidaerah, Diakses pada tanggal 05 Juli 2019.

http://pangestika14.blogspot.com/2013/ 09/dialek-wonosobo-pengkajianfolklore.html, diakses pada tanggal 05 juli 2019.

https://wijayadion004.wordpress.com/ke senian-khas-wonosobo/ diakses pada tanggal 30 Oktober 2019. 
